\title{
The LIFE child study: a life course approach to disease and health
}

\author{
Mirja Quante ${ }^{1,2,3 \dagger}$, Mara Hesse ${ }^{1,2 \dagger}$, Mirko Döhnert ${ }^{1,4}$, Michael Fuchs ${ }^{1,5}$, Christian Hirsch ${ }^{1,6}$, Elena Sergeyevev ${ }^{1,2}$, \\ Nora Casprzig', Mandy Geserick', Stephanie Naumann ${ }^{1}$, Christiane Koch ${ }^{1}$, Matthew A Sabin ${ }^{7,8}$, Andreas Hiemisch ${ }^{1,2}$, \\ Antje Körner ${ }^{1,2,3}$ and Wieland Kiess ${ }^{1,2,3^{*}}$, for the LIFE Child Study Investigators
}

\begin{abstract}
Background: Profound knowledge about child growth, development, health, and disease in contemporary children and adolescents is still rare. Epidemiological studies together with new powerful research technologies present exciting opportunities to the elucidation of risk factor-outcome associations with potentially major consequences for prevention, diagnosis and treatment.
\end{abstract}

Aim: To conduct a unique prospective longitudinal cohort study in order to assess how environmental, metabolic and genetic factors affect growth, development and health from fetal life to adulthood.

Methods: The 'Leipzig Research Centre for Civilization Diseases (LIFE) Child Study' focuses on two main research objectives: (1) monitoring of normal growth, development and health; (2) non-communicable diseases such as childhood obesity and its co-morbidities, atopy and mental health problems. Detailed assessments will be conducted alongside long-term storage of biological samples in 2,000 pregnant women and more than 10,000 children and their families.

Results: Close coordination and engagement of a multidisciplinary team in the LIFE Child study successfully established procedures and systems for balancing many competing study and ethical needs. Full participant recruitment and complete data collection started in July 2011. Early data indicate a high acceptance rate of the study program, successful recruitment strategies and the establishment of a representative cohort for the population of Leipzig. A series of subprojects are ongoing, and analyses and publications are on their way.

Discussion: This paper addresses key elements in the design and implementation of the new prospective longitudinal cohort study LIFE Child. Given the recognized need for long-term data on adverse effects on health and protective factors, our study data collection should provide magnificent opportunities to examine complex interactions that govern the emergence of non-communicable diseases.

Keywords: Cohort study, Children, Pregnancy, Life-course, Epidemiology

\footnotetext{
* Correspondence: contact@life.uni-leipzig.de

${ }^{\dagger}$ Equal contributors

${ }^{1}$ LIFE Leipzig Research Centre for Civilization Diseases, University of Leipzig,

Philipp-Rosenthalstrasse 27, D-04103 Leipzig, Germany

${ }^{2}$ Department of Women and Child Health, Hospital for Children and

Adolescents and Centre for Paediatric Research (CPL), University of Leipzig,

Liebigstrasse 20a, D-04103 Leipzig, Germany

Full list of author information is available at the end of the article
}

\section{() Biomed Central}

(c) 2012 Quante et al.; licensee BioMed Central Ltd. This is an Open Access article distributed under the terms of the Creative Commons Attribution License (http://creativecommons.org/licenses/by/2.0), which permits unrestricted use, distribution, and reproduction in any medium, provided the original work is properly cited. 


\section{Background}

Population-based cohort studies of children and birth cohort studies have made landmark contributions in identifying genetic and environmental factors that influence health and disease. In recent years, a variety of them have been established worldwide, and more are in progress. Important examples in Europe are the Avon Longitudinal Study of Parents and Children (ALSPAC), the Generations R Study, the Danish National Birth Cohort (DNBC) and the German Health Interview and Examination Survey for Children and Adolescents (KiGGS) [1-4].

\section{Why is there still relevance for a new population-based cohort study?}

The pace of development and change has accelerated exponentially since the beginning of the $20^{\text {th }}$ century and continues today, affecting many aspects of daily modern life. This implies that cohort studies will always reflect relatively contemporary exposures and practices. However, many ongoing birth cohorts began recruitment in the last century $[1,3,5]$. Ethnicity, different political and cultural backgrounds are associated with differences in disease prevalence. For example, there are large differences in prevalence of overweight and obesity among preschoolers across Europe [6]. Rapid development in research technologies and advancements in electronic data processing have increased the scope of what is possible to measure and include in epidemiological investigations. This emphasizes the need for contemporary populationbased cohort studies across different geographical regions.

\section{Scope of research}

The 'Leipzig Research Centre for Civilization Diseases (LIFE) Child Study' has been designed to understand how and through what mechanisms and mediators (epi) genetic, metabolic and environmental factors influence health and development in children and adolescents in modern society. The study is a prospective, longitudinal population-based cohort study of urban children from fetal life until adulthood. It focuses on two main research objectives: (1) monitoring of normal growth, development and health; (2) non-communicable diseases such as childhood obesity and its co-morbidities, atopy and mental health problems. Under the 'life course' conceptual model, risk factors during pregnancy and childhood alter the trajectories set by these early signals thus raising or lowering the risk of diseases. Therefore, ensuring salutogenic influences could entrain healthful trajectories of energy balance for life [7].

\section{Methods}

Study area, collaboration and overview

The LIFE Child study is a prospective longitudinal population-based cohort study with a life course approach to health and disease. A multi-professional team, including paeditricians, psychologists, sociologists, economists, psychiatrists, nutritional and sport scientists, ophthalmologists and dentists, has developed the conceptual framework of the study and established an administrative structure for the management and implementation of the study. Extensive assessments are carried out in pregnant women and their offspring and children and their families. The study collects detailed information from clinical examinations, questionnaires and interviews and includes a collection of several types of biological materials at various time points (see Tables 1, 2, 3, 4 and 5). Prenatal examinations are conducted during the $24^{\text {th }}$ to $26^{\text {th }}$ and $34^{\text {th }}$ to $36^{\text {th }}$ week of gestation. Birth is a crucial part of the study to collect cord blood, placental tissue and to obtain information about the labour and delivery from medical records. During the first year of life, data is collected from children at 3, 6 and 12 month of age. Moreover, a representative sample of children and adolescents (up to age 17.99 years) will be approached together with their families. Participants will be followed annually over a period of ten years irrespective of the age at the first participation in the study. In addition, the LIFE Child study focuses in certain disease cohorts and disease free controls in more detail. The aim of these subgroups is to examine aetiological associations with more in-depth methods that cannot be applied in the whole cohort due to time, financial and logistical constraints. So far, there are three disease cohorts: LIFE Child OBESITY, LIFE Child DEPRESSION and LIFE Child ATOPY. In the future, during the course of the study, additional disease cohorts might be conducted.

The LIFE Child study is part of LIFE, a life sciences research program of the University of Leipzig (Leipzig Research Centre for Civilization Diseases - LIFE). The measurements are performed in a well-equipped research centre located on the premises of the University Hospital of Leipzig. Big advantages are the proximity to the Hospital for Children and Adolescents, Department of Women and Child Health of the University of Leipzig, the LIFE Adult cohort and the IFB (Integrated Research and Treatment Centre Adiposity Diseases), as well as the basic research laboratories, hence allowing close interaction and addressing the objectives in an interdisciplinary approach. The LIFE Child study maintains a close collaborative network with the University of Leipzig, the Centre for Paediatric Research (CPL), the IFB, public health centres, schools and kindergartens, the faculty of education, the institute for medical informatics, statistics and epidemiology, the Helmholtz centre for environmental research, the $\mathrm{CrescNet}^{\circledR}$ network and with other national and international epidemiological research groups. 
Table 1 Assessments in the LIFE Child HEALTH and OBESITY cohorts

\begin{tabular}{|c|c|c|c|c|}
\hline & LIFE Child HEALTH cohort & & & LIFE Child OBESITY cohort \\
\hline Participant age & $0-2$ years & 2-6 years & $\geq 6$ years & $\geq 6$ years \\
\hline \multirow[t]{5}{*}{ Anthropometry } & - Weight & - Weight & - Weight & - Weight \\
\hline & • Height & - Height and sitting height & - Height and sitting height & - Height and sitting height \\
\hline & $\begin{array}{l}\text { - Head, arm, leg, waist, neck, } \\
\text { hip, thoracal and abdominal } \\
\text { circumference }\end{array}$ & $\begin{array}{l}\text { - Head, arm, leg, waist, neck } \\
\text { and hip circumference }\end{array}$ & $\begin{array}{l}\text { - Head, arm, leg, waist, } \\
\text { neck and hip circumference }\end{array}$ & $\begin{array}{l}\text { - Head, arm, leg, waist, } \\
\text { neck and hip circumference }\end{array}$ \\
\hline & - Biparietal diameter & - Skinfolds & - Skinfolds & - Skinfolds \\
\hline & - Blood pressure & - Blood pressure & - Blood pressure & - Blood pressure \\
\hline \multirow[t]{3}{*}{ Clinical exam } & $\begin{array}{l}\text { - Clinical history (perinatal } \\
\text { and past medical history, } \\
\text { medications, immunisations, } \\
\text { developmental history) }\end{array}$ & $\begin{array}{l}\text { - Clinical history (perinatal } \\
\text { and past medical history, } \\
\text { medications, immunisations, } \\
\text { developmental history) }\end{array}$ & $\begin{array}{l}\text { - Clinical history (perinatal } \\
\text { and past medical history, } \\
\text { medications, immunisations, } \\
\text { developmental history) }\end{array}$ & $\begin{array}{l}\text { - Clinical history (perinatal } \\
\text { and past medical history, } \\
\text { medications, immunisations, } \\
\text { developmental history, } \\
\text { specific details relating } \\
\text { to weight) }\end{array}$ \\
\hline & $\begin{array}{l}\text { - Clinical examination including } \\
\text { neurological examination and } \\
\text { pubertal assessment }\end{array}$ & $\begin{array}{l}\text { - Clinical examination } \\
\text { including neurological } \\
\text { examination and pubertal } \\
\text { assessment }\end{array}$ & $\begin{array}{l}\text { - Clinical examination } \\
\text { including neurological } \\
\text { examination and pubertal } \\
\text { assessment }\end{array}$ & $\begin{array}{l}\text { - Clinical examination } \\
\text { including neurological } \\
\text { examination and pubertal } \\
\text { assessment }\end{array}$ \\
\hline & $\begin{array}{l}\text { - Dental examination including } \\
\text { dentition and early childhood } \\
\text { caries }\end{array}$ & $\begin{array}{l}\text { - Dental examination } \\
\text { including dentition and } \\
\text { early childhood caries }\end{array}$ & $\begin{array}{l}\text { - Dental examination } \\
\text { (jaw models, dental caries, } \\
\text { periodontal disease, orofacial } \\
\text { pain, bruxism and tongue } \\
\text { function) }\end{array}$ & $\begin{array}{l}\text { - Dental examination } \\
\text { (jaw models, dental caries, } \\
\text { periodontal disease, } \\
\text { orofacial pain, bruxism } \\
\text { and tongue function) }\end{array}$ \\
\hline \multirow[t]{2}{*}{ Biological samples } & \multirow[t]{2}{*}{ - Blood, urine and hair } & \multirow[t]{2}{*}{ - Blood, urine and hair } & \multirow[t]{2}{*}{ - Blood, urine and hair } & - Oral glucose tolerance test \\
\hline & & & & - Blood, urine and hair \\
\hline Questionnaires & - See Table 4 & - See Table 4 & - See Table 4 & - See Table 4 \\
\hline \multirow{2}{*}{$\begin{array}{l}\text { Motor and cognitive } \\
\text { development }\end{array}$} & \multirow[t]{2}{*}{ - Bayley scales } & - Bayley scales (< 3.6 years) & \multirow[t]{2}{*}{ - Motor skills test } & \multirow[t]{2}{*}{ - Motor skills test } \\
\hline & & - Motor skills test (> 3.6 years) & & \\
\hline \multirow[t]{3}{*}{ Imaging } & \multirow{3}{*}{$\begin{array}{l}\text { - Cranial ultrasound } \\
\text { (3rd month of life) }\end{array}$} & & -3D-Bodyscan ${ }^{1}$ & -3D-Bodyscan ${ }^{1}$ \\
\hline & & & \multirow[t]{2}{*}{$\begin{array}{l}\text { - Sonography (heart, intima } \\
\text { media thickness, thyroid } \\
\text { and kidney², for a sub-sample) }\end{array}$} & $\begin{array}{l}\text { - Sonography (heart, intima } \\
\text { media thickness, thyroid } \\
\text { and kidney²) }\end{array}$ \\
\hline & & & & $\begin{array}{l}\text { - Magnetic resonance } \\
\text { imaging (for a sub-sample²) }\end{array}$ \\
\hline \multirow{3}{*}{$\begin{array}{l}\text { Cardiovascular and } \\
\text { pulmonary function } \\
\text { tests }\end{array}$} & & & \multirow[t]{3}{*}{ Spirometry } & - Spiroergometry \\
\hline & & & & - Spirometry \\
\hline & & & & - Endopat (for a sub-sample) \\
\hline \multirow{9}{*}{$\begin{array}{l}\text { Additional } \\
\text { assessments }\end{array}$} & & & - Voice examination ${ }^{1}$ & - Accelerometry \\
\hline & & & $\begin{array}{l}\text { - Prick test }{ }^{1,2} \text { (LIFE Child } \\
\text { ATOPY cohort) }\end{array}$ & - Resting electrocardiography \\
\hline & & & \multirow{7}{*}{$\begin{array}{l}\text { Optical coherence } \\
\text { tomography and } \\
\text { ophthalmoscopy } \\
\text { (for a sub-sample) }\end{array}$} & $\begin{array}{l}\text { - Indirect calorimetry } \\
\text { (for a sub-sample) }\end{array}$ \\
\hline & & & & - Voice examination \\
\hline & & & & - Electrical bioimpedance analysis \\
\hline & & & & $\begin{array}{l}\text { - Polysomnography } \\
\text { (for a sub-sample) }\end{array}$ \\
\hline & & & & - Eating behaviour test ${ }^{2}$ \\
\hline & & & & $\begin{array}{l}\text { - Optical coherence tomography } \\
\text { and ophthalmoscopy }{ }^{2}\end{array}$ \\
\hline & & & & $\begin{array}{l}\text { Prick test }{ }^{1,2} \\
\text { (LIFE Child ATOPY cohort) }\end{array}$ \\
\hline
\end{tabular}

\footnotetext{
${ }^{1}$ The assessment is combined with a specific questionnaire. ${ }^{2}$ Planned.
} 
Table 2 Assessments in the parents of the LIFE Child participants

\begin{tabular}{ll}
\hline Questionnaires and interview & Other assessments: \\
\hline - Clinical history & Buelogical samples: \\
& • Blood, urine and hair \\
& Anthropometry: \\
& - Weight \\
& $\cdot$ Height \\
& • Blood pressure \\
& Imaging: \\
& $\cdot$ 3D-Bodyscan \\
& Additional assessments: \\
& • Voice examination \\
\hline
\end{tabular}

\section{Study cohort}

The LIFE Child study will recruit a sample of 10,000 children and adolescents (LIFE Child HEALTH) and their families and 2,000 pregnant women (LIFE Child BIRTH) and their partners between July 2011 and July 2014. All children with their families and pregnant women of the area of Leipzig are eligible to participate in the LIFE Child study. This sample is supposed to represent the population of the city. The LIFE Child study consists of three disease cohorts: The LIFE Child OBESITY cohort is a sample of 1,500 obese children and adolescents that will be assessed and compared to a specific control group $(\mathrm{N}=1,500)$ with equally detailed phenotyping including metabolic and cardiovascular measurements. The LIFE Child DEPRESSION cohort is gathering data from a sample of 800 young patients (8-14 years) with psychopathological symptoms and a control sample of healthy children $(\mathrm{N}=400)$. Both samples will be assessed by means of a multi-informant, multi-method approach in 2-year follow-ups over 10 years. In the LIFE Child ATOPY cohort extra questionnaires and a prick test with common allergens in addition to the LIFE Child HEALTH program will be performed.

\section{Ethical issues}

The LIFE Child study like any other paediatric study encounters complex ethical issues [8]. These include the collection of data from minors, long-term biobanking of biological samples and subsequent genetic and epigenetic analysis and data privacy. The study was designed in accordance to the declaration of Helsinki [9]. The Ethics Committee of the University of Leipzig was involved in the study outline and approved the study (Reg. No. 26410-19042010). Fully informed and written consent is obtained for all participants and their parents. Starting at the age of twelve, written consent is also obtained from the children themselves. Participants are asked to re-consent at each study visit during complete course of the study. Consent for long-term use of data is sought. Moreover, participants are informed of their right to withdraw without explanations or adverse consequences at any time. A special two-pass encryption program is used to generate subject identifier codes (SIC) for all participants of the study in order to pseudo-anonymise their data. Both an internal and an independent external ethical advisory board have been established.

\section{Recruitment and attrition}

The LIFE Child study decided to employ a variety of recruitment strategies. The overall approach is a community-

Table 3 Assessments in the mothers of the LIFE Child BIRTH cohort

\begin{tabular}{|c|c|c|c|c|}
\hline & $24^{\text {th }}-26^{\text {th }}$ week of gestation & $34^{\text {th }}-36^{\text {th }}$ week of gestation & Delivery & $3^{\text {rd }}, 6^{\text {th }}$ and $12^{\text {th }}$ month postpartum \\
\hline \multirow[t]{4}{*}{ Anthropometry } & - Weight & - Blood pressure & & - Weight \\
\hline & - Height and sitting height & & & - Height and sitting height \\
\hline & $\begin{array}{l}\text { - Head, arm, leg, waist, } \\
\text { neck and hip circumference }\end{array}$ & & & $\begin{array}{l}\text { - Head, arm, leg, waist, neck and } \\
\text { hip circumference }\end{array}$ \\
\hline & - Blood pressure & & & - Blood pressure \\
\hline \multirow[t]{2}{*}{ Imaging } & - 3D-Bodyscan & -3D-Bodyscan & & -3D-Bodyscan \\
\hline & - Ultrasound data of fetal size & - Ultrasound data of fetal size & & \\
\hline \multirow{2}{*}{$\begin{array}{l}\text { Biological } \\
\text { samples }\end{array}$} & - Blood, urine and hair & - Blood, urine and hair & \multirow{2}{*}{$\begin{array}{l}\text { - Cord blood, biopsies } \\
\text { of the placenta and } \\
\text { the umbilical cord }\end{array}$} & - Blood, urine and hair \\
\hline & - Oral glucose tolerance test & & & - Breast milk \\
\hline \multirow[t]{3}{*}{ Clinical exam } & \multirow{2}{*}{$\begin{array}{l}\text { - Family history and } \\
\text { history of pregnancy }\end{array}$} & \multirow{2}{*}{$\begin{array}{l}\text { - Follow-up history of } \\
\text { pregnancy }\end{array}$} & & - Follow-up history of pregnancy \\
\hline & & & & - History of delivery \\
\hline & - Current medications & - Current medications & & - Current medications \\
\hline Questionnaires & - See Table 4 & - See Table 4 & & - See Table 4 \\
\hline
\end{tabular}

Assessments in the child (see Table 1)

Evaluations during pregnancy are planned in the $24^{\text {th }}-26^{\text {th }}$ week of gestation and in the $34^{\text {th }}-36^{\text {th }}$ week of gestation. During the first year of their offspring's life three visits in the study centre are planned. 
Table 4 Content of questionnaires, interviews and psychological tests

\section{LIFE Child HEALTH cohort}

Child participant

information (to be

completed by the

parent and/or child)

Environment Sociodemography

Lifestyle (sexual

development, addictive

behaviour, media use,

sports, spare time

interaction .... $)^{1}$

Quality of life $(\geq 10$

years)

Physical and

psychological

well-being, autonomy

and parents, peers

and social support

and school environment

$(>8 \text { years })^{1}$

$\begin{array}{ll}\begin{array}{l}\text { Physical } \\ \text { Health }\end{array} & \text { Health-related } \\ & \text { symptoms }^{1} \\ & \text { Alternative medicine }^{1} \\ & \text { Allergies }^{1} \\ & \text { Sleep behaviour } \\ & { }^{1} \\ & \text { Child feeding } \\ & (2-13 \text { years) } \\ & \text { Eating disorders } \\ & (\geq 8 \text { years })^{1}\end{array}$

\section{Parent participant}

information (to be

completed by the

parent)

\section{LIFE Child OBESITY cohort}

Child participant
information (to be
completed by the

parent and/or child)

Sociodemography

Lifestyle (sexual

development,

Lifestyle (sexual

development, addictive

behaviour, media use,

sports, spare time

media use, sports,

activities, social

social interaction ...) interaction ... $)^{1}$

Quality of life

Impact of health

conditions $^{1}$

Physical and

psychological

well-being, autonom

and parents, peers

and social support

and school environment

(> 8 years)

Health-related

symptoms

Alternative medicine

Allergies $^{1}$

Sleep behaviour ${ }^{1}$

Sleep behaviour ${ }^{1}$

Child feeding

(2-13 years)

Eating disorders

$(\geq 8 \text { years })^{1}$

Nutrition diary ${ }^{?}$

\section{LIFE Child DEPRESSION cohort}

LIFE Child BIRTH

cohort

\section{Parent participant \\ information (to be}

completed by the

parent)

information (to be

completed by the

parent and/or child)

Sociodemography

Lifestyle (sexual

development,

addictive behaviour,

media use, sports,

spare time activities,

social interaction ....

Lifestyle (sexual

development, addictive

behaviour, media use,

sports, spare time

activities, social

interaction ...)

Quality of life

Physical and

psychological well-

being, autonomy and

parents, peers and socia

support and school

environment ( $>8$ years)

Parent participant

information (to be

completed by the

parent)

Characteristics of

family environment ${ }^{1}$

egnant woman

participant

information (to be

completed by the

pregnant woman)

Sociodemography ${ }^{1}$

Lifestyle (sexual

development, addictive

behaviour, media use,

sports, spare time

activities, socia

interaction ....)

Parental stress

Peer relationship

Parenting ${ }^{1}$

Health-related

symptoms

Parenting ${ }^{1}$

Physical health

Screening ${ }^{1}$

Alternative medicine ${ }^{1}$

Allergies

Sleep behaviour ${ }^{1}$

Sleep behaviour

Allergies ${ }^{1}$

Sleep behaviour ${ }^{1}$

Nutrition diary 
Table 4 Content of questionnaires, interviews and psychological tests (Continued)

\begin{tabular}{|c|c|c|c|c|c|c|c|}
\hline \multirow[t]{2}{*}{$\begin{array}{l}\text { Family and } \\
\text { School }\end{array}$} & & $\begin{array}{l}\text { Self-assessed } \\
\text { partner-attachment }^{1}\end{array}$ & & $\begin{array}{l}\text { Self-assessed } \\
\text { partner-attachment }^{1}\end{array}$ & & & $\begin{array}{l}\text { Self-assessed } \\
\text { partner-attachment }^{1}\end{array}$ \\
\hline & $\begin{array}{l}\text { Performance at } \\
\text { school }(\geq 6 \text { years) })^{1}\end{array}$ & & Performance at school ${ }^{1}$ & & Performance at school ${ }^{1}$ & & \\
\hline \multirow[t]{8}{*}{ Mental Health } & & & & & Symptom Screening ${ }^{1}$ & $\begin{array}{l}\text { Mental health } \\
\text { Screening }\end{array}$ & \\
\hline & & & $\begin{array}{l}\text { Attention deficit/ } \\
\text { Hyperactivity symptoms }\end{array}$ & & $\begin{array}{l}\text { Attention deficit/ } \\
\text { Hyperactivity symptoms' }\end{array}$ & & \\
\hline & & & $\begin{array}{l}\text { Perception of teasing } \\
(\geq 10 \text { years })^{1}\end{array}$ & & & & \\
\hline & Life events ( $\geq 10$ years) ${ }^{1}$ & & Life events ( $\geq 10$ years) ${ }^{1}$ & & $\begin{array}{l}\text { Life events, neglect, } \\
\text { physical/emotional/ } \\
\text { sexual abuse } 1,2\end{array}$ & & \\
\hline & $\begin{array}{l}\text { Mental disorders } \\
(\geq 18 \text { years })^{1}\end{array}$ & Mental disorders ${ }^{1}$ & $\begin{array}{l}\text { Mental disorders ( } \geq 18 \\
\text { years) }\end{array}$ & Mental disorders ${ }^{1}$ & Psychiatric diagnoses $^{2}$ & & Mental disorders ${ }^{1}$ \\
\hline & $\begin{array}{l}\text { Illness behaviour and } \\
\text { somatoform disorders } \\
(9 \text { and } 12 \text { years })^{1}\end{array}$ & & $\begin{array}{l}\text { Illness behaviour and } \\
\text { somatoform disorders ( } 9 \\
\text { and } 12 \text { years) }\end{array}$ & & Somatic complaints ${ }^{1}$ & & \\
\hline & & & & & Anxiety symptoms ${ }^{1}$ & & \\
\hline & & & & & Depressive symptomes ${ }^{1}$ & & \\
\hline \multirow[t]{8}{*}{ Personality } & $\begin{array}{l}\text { Personality (Big five } \\
\text { concept) }(\geq 18 \text { years) }\end{array}$ & $\begin{array}{l}\text { Personality } \\
\text { (Big five concept) }^{1}\end{array}$ & $\begin{array}{l}\text { Personality (Big five } \\
\text { concept) }(\geq 18 \text { years) }\end{array}$ & 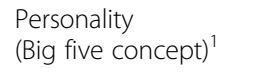 & & & $\begin{array}{l}\text { Personality (Big five } \\
\text { concept) }\end{array}$ \\
\hline & $\begin{array}{l}\text { Risk and sensation } \\
\text { seeking behaviour } \\
(\geq 4 \text { years })^{1}\end{array}$ & & $\begin{array}{l}\text { Risk and sensation } \\
\text { seeking behaviour }\end{array}$ & & & & \\
\hline & $\begin{array}{l}\text { Control and } \\
\text { competence beliefs } \\
\text { ( } \geq 4 \text { years })^{1}\end{array}$ & & $\begin{array}{l}\text { Control and } \\
\text { competence beliefs }\end{array}$ & & & & \\
\hline & $\begin{array}{l}\text { Strengths and } \\
\text { weaknesses ( } \geq 3 \text { years })^{1}\end{array}$ & & $\begin{array}{l}\text { Strengths and } \\
\text { weaknesses }^{1}\end{array}$ & & & & \\
\hline & $\begin{array}{l}\text { Body attitudes } \\
(\geq 8 \text { years })^{1}\end{array}$ & & $\begin{array}{l}\text { Body attitudes } \\
{\text { } \geq 8 \text { years })^{1}}\end{array}$ & & & & \\
\hline & & & & & Social competence ${ }^{1}$ & & \\
\hline & & & & & Self perception ${ }^{1}$ & & \\
\hline & & & & & Intelligence ${ }^{3}$ & & \\
\hline
\end{tabular}


Table 5 Biobank blood sample collection and parameters of direct analysis

\begin{tabular}{ll}
\hline Participant age & Maximum volume of stored \\
\hline Birth & $24 \times 0.3 \mathrm{ml}$ (EDTA, SG) \\
& $4 \times 0.3 \mathrm{ml}$ (EDTA, SG) \\
$\mathbf{6}$ Month & $6 \times 0.3 \mathrm{ml}$ (EDTA, SG) \\
& $8 \times 0.3 \mathrm{ml}$ (EDTA, SG) \\
$\mathbf{1}$ - $\mathbf{3}$ years & $3 \mathrm{ml}$ (Blood RNA tube) \\
& $10 \times 0.3 \mathrm{ml}$ (EDTA, SG) \\
$\mathbf{3}$ - $\mathbf{6}$ years & $3 \mathrm{ml}$ (Blood RNA tube) \\
& $4 \mathrm{ml}$ (Cell preparation tube) \\
& $12 \times 0.3 \mathrm{ml}$ (EDTA, SG) \\
$\mathbf{6}$ - $\mathbf{8}$ years & $3 \mathrm{ml}$ (Blood RNA tube) \\
& $4 \mathrm{ml}$ (Cell preparation tube)
\end{tabular}

\begin{tabular}{|c|c|}
\hline \multirow[t]{3}{*}{$8-14$ years } & $20 \times 0.3 \mathrm{ml}($ EDTA, SG) \\
\hline & $3 \mathrm{ml}$ (Blood RNA tube) \\
\hline & $8 \mathrm{ml}$ (Cell preparation tube) \\
\hline \multirow[t]{3}{*}{$>14$ years } & $26 \times 0.3 \mathrm{ml}(\mathrm{EDTA}, \mathrm{SG})$ \\
\hline & $3 \mathrm{ml}$ (Blood RNA tube) \\
\hline & $8 \mathrm{ml}$ (Cell preparation tube) \\
\hline \multirow[t]{3}{*}{ Parents } & $24 \times 0.3 \mathrm{ml}(\mathrm{EDTA}, \mathrm{SG})$ \\
\hline & $3 \mathrm{ml}$ (Blood RNA tube) \\
\hline & $8 \mathrm{ml}$ (Cell preparation tube) \\
\hline \multirow{3}{*}{$\begin{array}{l}\text { Pregnant Women } \\
\left(24^{\text {th }}-26^{\text {th }} \text { week of gestation, }\right. \\
34^{\text {th }}-36^{\text {th }} \text { week of gestation } \\
\text { and visits postpartum) }\end{array}$} & $30 \times 0.3 \mathrm{ml}(\mathrm{EDTA}, \mathrm{SG})$ \\
\hline & $3 \mathrm{ml}$ (Blood RNA tube) \\
\hline & $8 \mathrm{ml}$ (Cell preparation tube) \\
\hline
\end{tabular}
Direct analysis

Not performed

Electrolytes, bilirubin, protein, creatinin kinase, lipid profile, full blood count, thyroid function test, proinflammatoric cytokines, bone parameters, vitamins, NT-pro-BNP, growth hormones

Electrolytes, bilirubin, protein, creatinin kinase, lipid profile, full blood count, thyroid function test, proinflammatoric cytokines, bone parameters, vitamins, allergy testing, troponin T, NT- pro-BNP, growth hormones

Electrolytes, protein, creatinin kinase, lipid profile, full blood count, thyroid function test, proinflammatoric cytokines, bone parameters,vitamins, allergy testing, troponin T, NT- pro-BNP, growth hormones, liver function tests, renal function tests, transferrin, sex steroids

Electrolytes, protein, creatinin kinase, lipid profile, full blood count, thyroid function test, proinflammatoric cytokines, bone parameters,vitamins, allergy testing, troponin T, NT- pro-BNP, growth hormones, liver function tests, renal function tests, transferrin, ferritin, sex steroids

Electrolytes, protein, creatinin kinase, lipid profile, full blood count, thyroid function test, proinflammatoric cytokines, bone parameters,vitamins, allergy testing, troponin T, NT- pro-BNP, growth hormones, liver function tests, renal function tests, transferrin, glucose, insulin, sex steroids

\section{LIFE Child OBESITY cohort and controls :}

+ Oral glucose tolerance test, proinsulin, c-peptide, uric acid

See $6-8$ years

See $6-8$ years

Not performed

Electrolytes, protein, creatinin kinase, lipid profile, full blood count, thyroid function test, proinflammatoric cytokines, bone parameters,vitamins, allergy testing, growth hormones, liver function tests, renal function tests, transferrin,glucose, insulin, sex steroids, oral glucose tolerance test

$34^{\text {th }}-36^{\text {th }}$ week of gestation: no oral glucose tolerance test

Visits postpartum: no renal function tests

Number of samples $x$ volume collection. EDTA, Ethylene-Diamine-Tetra-Acetic acid tube. SG, Serum Gel tube. $L H$, Lithium Heparin tube. NT-pro-BNP, N-terminal pro-Brain Natriuretic Peptide. RNA, Ribonucleic acid.

based collaborative network of university hospitals, local clinics, public health centres, kindergartens, schools and partner study centres like the IFB (see Figures 1, 2 and 3). Specific contact information is given to participants at the time of recruitment. Telephone and email reminders are performed. A variety of items embossed with the study logo (see Figure 4), a green amphibian, as well as small monetary incentives (not more than 20 Euro per child) are given to participants at the time of recruitment to compensate for their time [10]. Pregnant women are also offered an ultrasound video of their baby. Recruitment goals are continuously monitored and strategies are adapted. The researchers send Christmas and birthday cards and newsletters to encourage continued participation. Study promotion like presentations, forums, fliers/posters, press releases and TV spots is targeted at potential participants. Regular feedback on results will be provided. As retention involves building relationships with participants several events like children's parties and sport events (e.g. running) are arranged. Several German cohort studies have already shown high enrolment and follow-up rates. This might be due to the fact that the German population, especially in East Germany, is apparently more compliant with the participation in research projects in comparison with other countries $[5,11]$. People who voluntarily contact the study centre for participation tend to be different from other people in terms of basic demographic factors (e.g. social class, level of education and core personality traits). To 


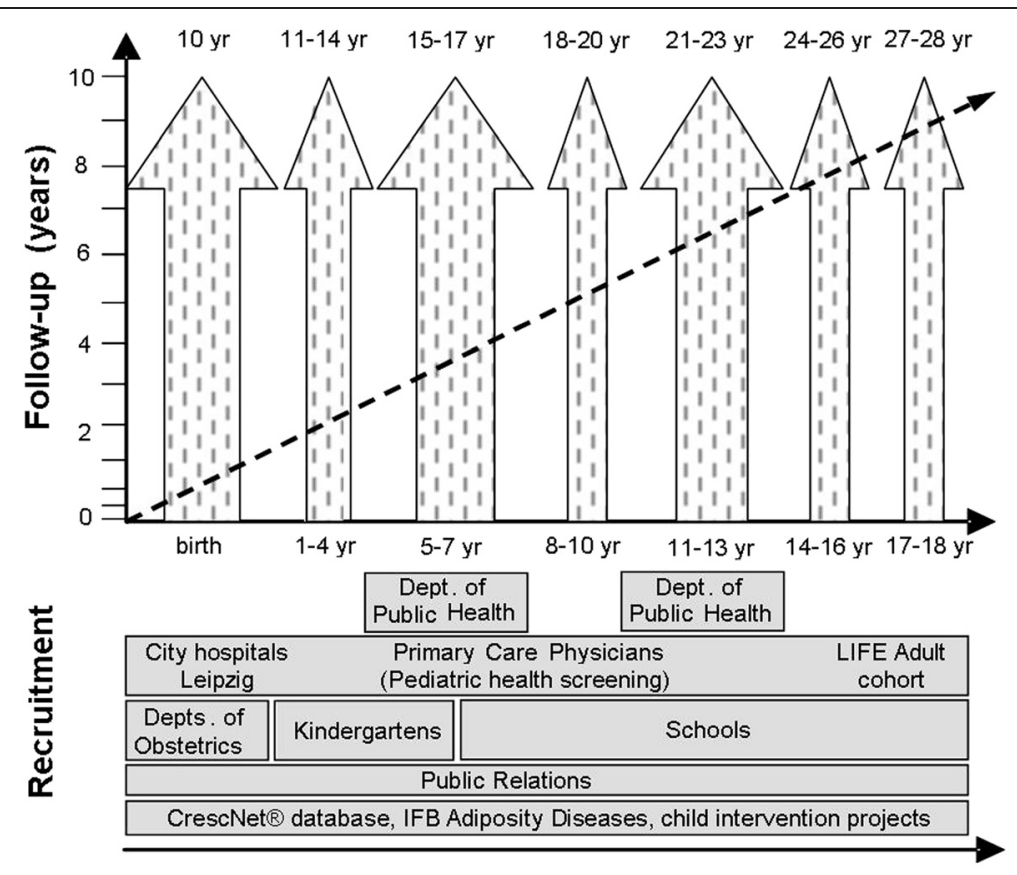

Figure 1 Strategies of recruitment. Strategies of recruitment and favoured sampling sizes depending on the age at the first participation.

minimize this bias, whole school classes, especially from the inner cities with a lower social background are approached. Dropouts and refusals to participate can lead to selection bias due to differences between participants who remain in the study and dropouts [12]. Therefore, questionnaires requesting the underlying causes will be sent to the families and several research projects addressing dropout issues have been initiated.

\section{Assessments}

There is a basic program that will be carried out at each study centre visit. This program includes clinical history (perinatal and past medical history, medications, allergies, immunizations, developmental history and family history) clinical examination, collection of blood, hair and urine samples, anthropometry and different age-dependent questionnaires (see Table 4). Questionnaires are completed by the parents and starting at the age of eight years also by the child itself. They are standardized, validated, published, computerized and piloted. Whenever possible mother, father and even the teacher of the child are asked to answer the questionnaires separately. Additional assessments are added at different ages or in subgroups. The development of children beginning at the age of three months until $3 \frac{1}{2}$ years of age is evaluated by psychologists using the newly developed

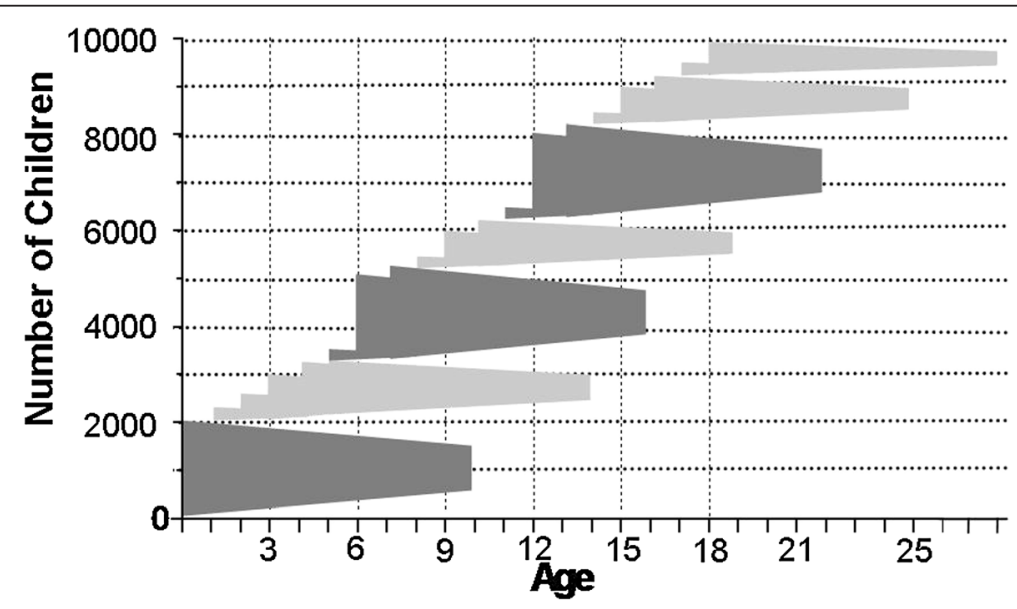

Figure 2 Numbers of participants to be recruited in the different age groups. 


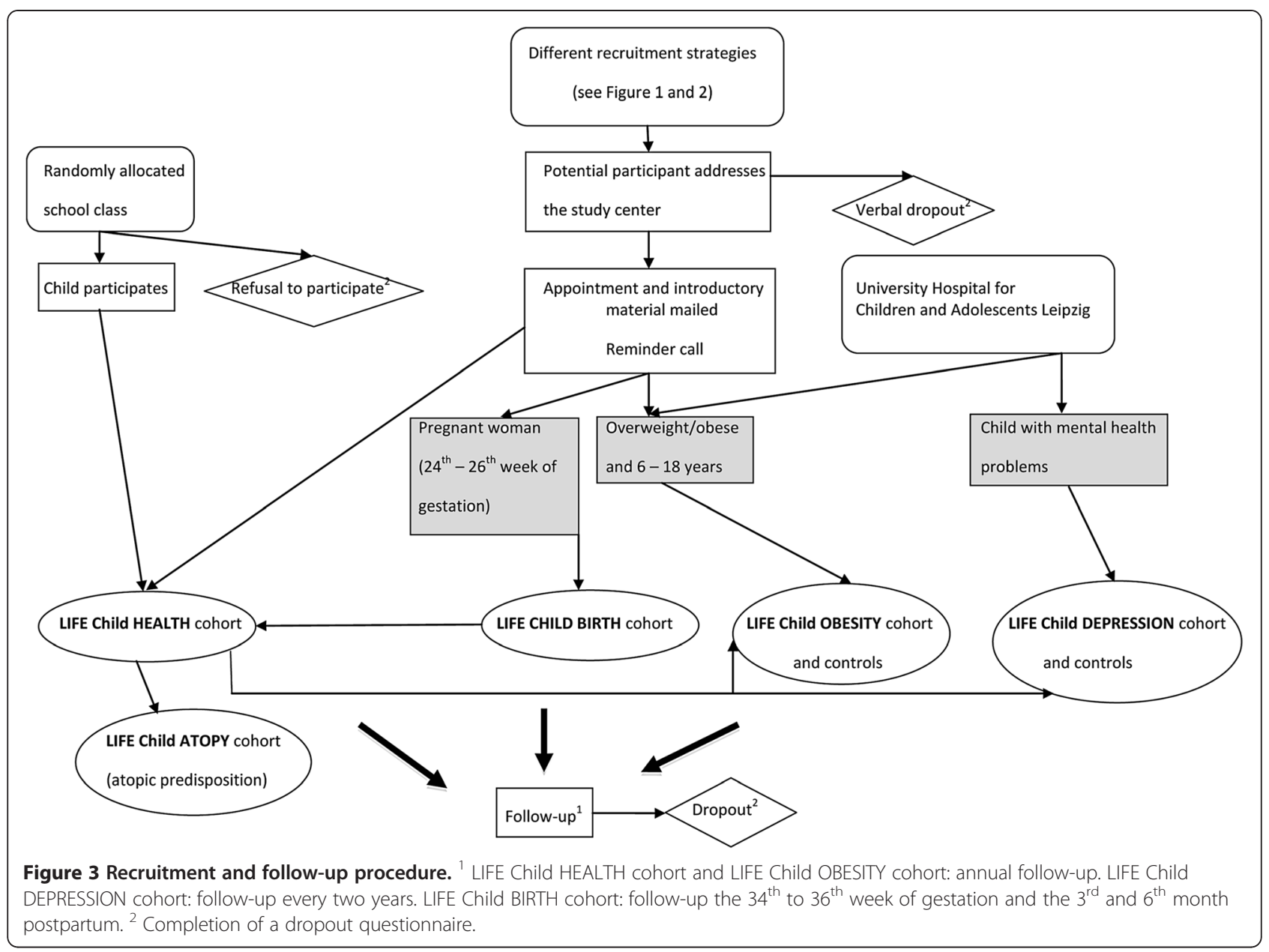

third edition of the Bayley Scales of Infant and Toddler Development ${ }^{\circledR}$ (Bayley-III ${ }^{\circledR}$ ) [13]. In close collaboration with the developers of these scales - Pearson Clinical

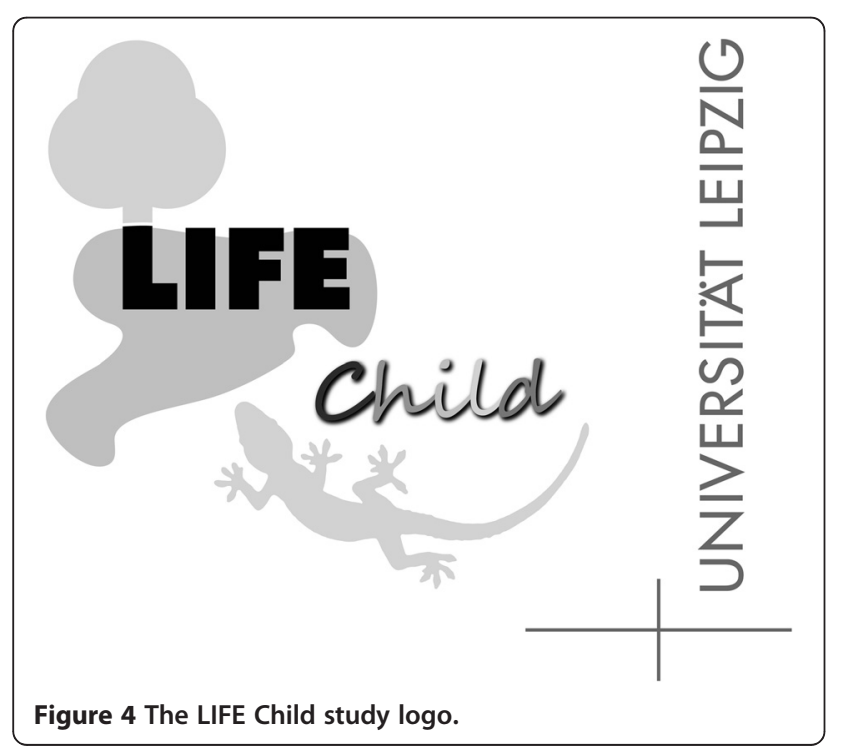

Assessments - and other study centres, LIFE Child study will contribute to the German standardization of this new edition. Beginning at the age of $3 \frac{1}{2}$ years, all children attend a motor skills examination. At the age of six years, lung function testing (spirometry), a voice examination and a body scan are added. The 3D body scanner (VITUS XXL 3D) is a measuring tool for a rapid quantification of body shape [14]. In LIFE Child study, it is used for anthropometric investigations. Within a few seconds, the whole body of the participant is scanned with non-hazardous laser beams and a 3D figure appears on the attached computer screen. The results of the body scanner will be compared to the results of the classic anthropometry to evaluate whether the body scanner can replace measuring tape, scales and stadiometers in the future. Another unique assessment is the voice examination, which will allow to explore genetic and environmental effects on the voice [15]. Voice limits are measured in a standardized fashion (sound-pressure levels in dependence of frequency) when the participants speak and sing. These data will provide clinically relevant information about the volume and pitch range of 
the voice [16]. The often underestimated oral diseases have profound effects on general health and quality of life [17]. The social impact of diseases like dental caries, periodontal diseases and orofacial pain in children is substantial. Worldwide more than 50 million school hours are lost each year to dental-related illness and especially children with lower social background are affected [18]. Therefore, dental examinations including jaw models and evaluation of dental caries, periodontal disease, orofacial pain, bruxism and tongue function are performed. In the LIFE Child OBESITY cohort (including the control group), additional parameters such as electrical bioimpedance, assessment of basal metabolic rate, oral glucose tolerance test, spiroergometry and measurement of endothelial function using EndoPAT $^{\circledR}$ are assessed. The oral glucose tolerance test (oGTT) is performed with insulin and glucose measured every 15-30 min between 0 and $120 \mathrm{~min}$. It is assumed that this approach with close measurement intervals will allow a better insight into metabolic processes. The EndoPAT $^{\circledR} 2000$ (Itamar Medical Inc., Caesarea, Israel) is a device to measure peripheral arterial tonometry PAT - signals. It has been validated and used in several studies to analyze the reactive hyperaemia index (RHI), which quantifies the dilatation response of peripheral vessels to increased blood flow following suprasystolic occlusion [19-21]. A low RHI has been shown to be associated with endothelial dysfunction and a higher risk for existent or future cardiovascular events [22]. Tables 1 , 2, 3, 4 and 5 show all the parameters collected in the LIFE Child study. More detailed information on the LIFE Child study protocol is available upon request and on our homepage (http://www.uni-leipzig-life.de) to any researcher interested in the program.

\section{Biological samples}

In accordance with the COBRA project (Childhood Overweight BioRepository of Australia project) the LIFE Child study team established a unique 'biorepository' of data and biological samples of the cohort [23]. Blood, urine and hair samples are collected from each study subject and its parents annually. The volume of the blood withdrawal has been adjusted to the age and body weight of the children. Some blood parameters are analyzed directly. These parameters cover several areas of particular health interest like micronutrient deficiency, sero-epidemiology, growth and sexual hormones and risk indicators for different diseases (see Table 5). To minimize the possibility of degradation, the plasma and serum samples for future investigations are biobanked in small aliquots $(300 \mu \mathrm{l})$ and stored at $-140^{\circ} \mathrm{C}$ [24]. Genomic DNA, dried blood spots, paxgenes (for RNA isolation and expression/eQTL studies) and immortalized lymphocytes are stored at $-80^{\circ} \mathrm{C}$. At delivery umbilical cord blood, the umbilical cord itself and placental biopsies are stored in the biobank. The biopsies are stored at $-80^{\circ} \mathrm{C}$, while the cord blood is aliquoted and biobanked at $-140^{\circ} \mathrm{C}$. Breast milk is known to contain many bioactive hormones and peptides, which may play important roles in neonatal health and development. For example researchers of the LIFE Child study team could show that infants' body weight gain may be influenced by milk leptin concentrations [25]. Breast milk is collected and stored at $-80^{\circ} \mathrm{C}$ from lactating mothers the third and sixth month postpartum.

\section{Quality management issues}

For epidemiological research, accuracy and reliability of the measurements used are extremely important considerations. Quality management in the LIFE Child study involves multiple levels of training, monitoring and feedback activities, including: certification of research personnel for all specialized testing procedures and for data entry, documentation of all procedures in a written and web-accessible manual of procedures and ongoing monitoring of data quality. Several feasibility studies have been carried out to evaluate different assessments. A pilot study was performed to test the complete study protocol. This project with 200 normal weight and 200 obese participants was finished in December 2011. The experiences have been applied to optimize the operational sequences of the LIFE Child study. Since the quality of data from participants of the pilot phase was comparable to those collected later on, data have now been included in the total cohort. All different assessments are performed and evaluated by a well-trained team of physicians, nurses, technical assistants, psychologists, dentists, sport and nutritional scientists. Documents outlining the standard operating procedures (SOPs) exist for all assessments. The completeness, consistency and plausibility of all collected data are controlled regularly and in a standardized fashion using computation of the data. In addition to internal quality management, an external scientific advisory board was established to supervise the study.

\section{Incidental findings and disclosure of results}

Newest research technologies applied in large cohorts may lead to unexpected results. These incidental findings are defined as unexpected findings discovered in the course of research but 'beyond the aims of the study' [26]. Policies addressing various categories of findings and plans for their handling have been established. At the end of each study visit the participating families are invited to a personal conversation with one of the physicians to receive a short feedback on the results of the routine measurements, such as physical measures (weight and height). Any results that meet the requirements of scientific 
validity, clinical significance and benefit, such as prevention or treatment measures are reported to the family and with the parent's consent also to the family's primary care physician $[27,28]$. Additional diagnostic or therapeutic steps are given to the discretion of the family and fall into the responsibility of the family's primary care physician. In cases of doubt whether a finding should be reported to the families or not, the ethical advisory boards and medical experts are being asked for advice and their decisions are documented for future decision taking. When situations of suspected child abuse/neglect are encountered the LIFE Child team is aware of legal obligations to report this information to authorities.

\section{Research projects}

A short description of the specific aims, measurements and projects of the LIFE Child study is given here:

\section{Growth, development and health (the LIFE Child HEALTH cohort)}

Genetics and perinatal conditions such as social and environmental determinants are major factors influencing growth, development, health and disease outcomes including all-cause mortality and cardiovascular disease [29]. Some of the research questions that will be addressed are:

(1) Which fetal and infant growth patterns are associated with the development of risk factors for non-communicable diseases such as obesity, cardiovascular diseases and atopy?

(2) Which environmental factors and genetic variants are determinants of normal and abnormal growth, development and health?

(3) How are normal growth, physical activity and cognitive development defined in modern society?

Measurements planned and biological samples collected in the LIFE Child HEALTH cohort are listed in Table 1,4 and 5 .

\section{Pregnancy and offspring (the LIFE Child BIRTH cohort)}

The LIFE Child study also includes a birth cohort. In this cohort the influence of antenatal factors on growth and neurobehavioral outcomes will be investigated. Prenatal visits are conducted during the $24^{\text {th }}$ and the $26^{\text {th }}$ week of gestation with a follow up ten weeks later (see Table 3). During the first year of life, data from newborns is collected at 3, 6 and 12 month of age. The child is then integrated into the LIFE Child HEALTH cohort. In order to enable and improve the collaboration with other birth cohorts, the LIFE Child BIRTH cohort is already listed on the website birthcohorts.net [30]. Research questions that will be addressed include:

(1) What are the interactions between gestational environmental factors (e.g. maternal diet) and susceptibility genes in the development of noncommunicable diseases such as obesity, cardiovascular diseases and atopy?

(2) What specific determinants underlie the differences in birth outcomes?

(3) What are the prenatal and early postnatal determinants of normal and abnormal growth, physical and cognitive development?

3. Childhood overweight and obesity (the LIFE Child OBESITY cohort)

The rates of overweight and obesity are unacceptably high, with significant sequelae for the health and wellbeing of affected children. The pathogenesis of obesity related comorbidities such as metabolic disorders and cardiovascular disease already starts in childhood [31]. Therefore, identifying predisposing and protective environmental and genetic factors and subsequent prevention and therapy of early onset obesity have become a major focus in research $[32,33]$. The LIFE Child OBESITY cohort will be established as a well-characterized cohort of overweight and obese children and adolescents compared to healthy normal weight controls (see Table 1). All participants also undergo the complete LIFE Child HEALTH program. For the purposes of recruitment overweight and obesity are classified using the $90^{\text {th }}$ and $97^{\text {th }}$ body mass index (BMI) percentile cut-offs of Kromeyer-Hauschild, as these classification is routinely used in Germany [34,35]. Worldwide several other systems for classification, such as the World Health Organization (WHO) criteria or the ones of the International Obesity Task Force (IOTF) exist [36]. Therefore, the LIFE Child study always includes a data set with raw height, weight and BMI to enable researchers to use other classifications when it comes to data analysis. Some of the research questions that will be addressed are:

(1) What are the biological, genetic, social and behavioural determinants and consequences of childhood obesity?

(2) Which specific factors lead to an increased risk of later weight-related comorbidities?

(3) Which genetic and environmental determinants are associated with long-term weight loss or weight maintenance?

4. Mental health (the LIFE Child DEPRESSION cohort) 
Depressive disorders are more and more present even in young children. The most prevalent problems are behavioural and emotional disorders and hyperactivity [37]. Since nowadays health sciences focus on a salutogenetic approach, the quest for protective factors on mental development and health has increasingly gained importance [38]. Several genetic, demographic, psychosocial, cognitive and biological correlates of onset and course of mental health problems such as early-onset depression have already been identified. Unfortunately, little is known about the interactions of these factors [39]. Research questions that will be addressed include:

(1) What are determinants of normal and abnormal mental and social development?

(2) What are determinants of depressive disorders in children, adolescents and young adults?

(3) What influences the developmental course of emotional symptoms and affective disorders between childhood and early adulthood?

Measurements planned in the LIFE Child DEPRESSION cohort are listed in Table 4.

\section{Atopy (the LIFE Child ATOPY cohort)}

Asthma and allergies have become increasingly prevalent during recent years [40-42]. The rapid increase of their prevalence in East Germany after the German reunification implies an association with lifestyle changes [43]. Therefore, the family history and questionnaires concerning atopic symptoms together with blood parameters like IgE concentrations specific for different food allergens and aeroallergens are assessed in the LIFE Child HEALTH cohort and allow to define a subcohort of clinically manifested or predisposed participants. In this LIFE Child ATOPY cohort additional questionnaires and a prick test with common allergens will be performed. Research questions include:

(1) What is the overall incidence of atopy from birth to adulthood?

(2) What are the underlying interactions between environmental and genetic determinants that lead to atopy?

\section{Results}

Close coordination and engagement of a multidisciplinary team in LIFE Child successfully established procedures and systems for balancing many competing study and ethical needs. By means of quality management, daily operating procedures have been improved before data collection for the main study of LIFE Child started in July 2011. Until August $31^{\text {st }} 2012,1,382$ children and their families and 112 pregnant women have attended at least one appointment in the study centre and 212 follow-up visits have already been executed. Moreover, 96 babies were enrolled at birth. In the LIFE Child DEPRESSION cohort 207 children (including clinicreferred and healthy children) participated. We were literally overwhelmed by the success of our recruitment strategies with 534 families still being on the waiting list for participation in the LIFE Child study. Figure 5 shows the steady increase of participant numbers over time. Initial data suggest that the cohort will be representative for the population of Leipzig and indicate a high acceptance rate of the study program and the different assessments. For example, preliminary data on the acceptance revealed that the overall response was very positive with $89 \%$ of the children and their families planning to definitely come again for follow-up. Detailed analyses on dropout rates and the acceptance of the study program are on the way and will be published elsewhere. Initial data from school classes enrolled in the study show that boys are more likely to attend lower level education schools than girls while girls are overrepresented in the higher educational tracts. Data on the overall frequency of incidental findings, the gender- and age-specific distribution and the frequency with which clinical action is taken as a result of discovering an incidental finding are going to be reported elsewhere.

\section{Discussion}

Like any other comparable study, the LIFE Child study has its strengths and limitations. Some of the main strengths are the large sample size of the cohort, the longitudinal design of the study and the broad age range. Longitudinal studies in general have many advantages compared to cross-sectional studies like the reduction of retrospective bias from the participants, the possibility to take biological samples at different time points and the

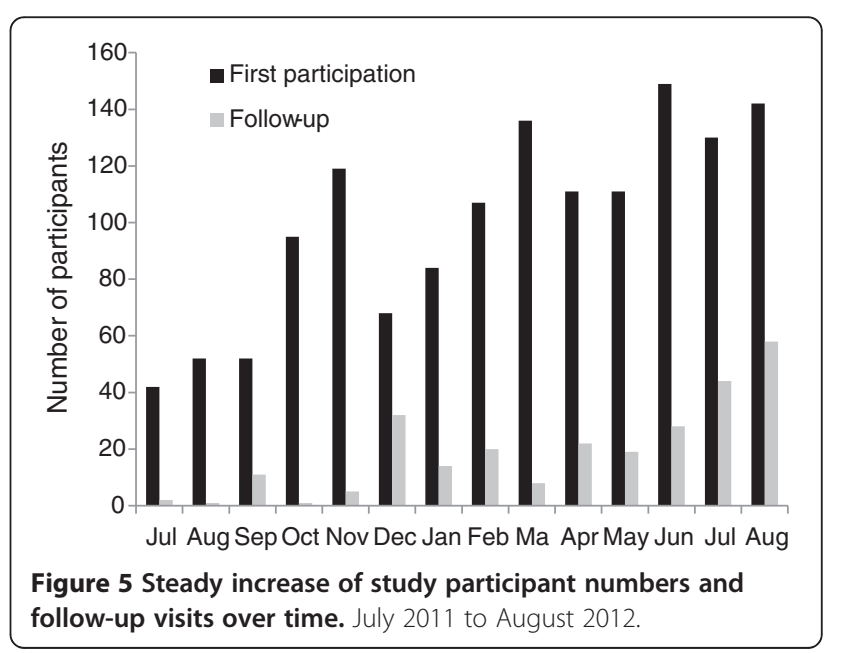


monitoring of changes with age [44]. Further advantages of the LIFE Child study are the multidisciplinarity and close collaboration with the University of Leipzig and diverse research centres like the IFB, the Helmholtz centre for environmental research and the LIFE Adult cohort. The LIFE Child study has an open policy in regard to collaboration with other research groups. Compared to other planned or recently started population-based cohort studies, the size of the LIFE Child study is not larger but the measurements are more detailed [2,3]. For example biological samples are obtained from all participants and their parents at each follow-up visit. By this a 'biorepository' containing a longitudinal collection of samples starting in the early stages of life and childhood from each participant will be established that provides a unique and powerful opportunity to monitor metabolic and epigenetic changes over time [45]. A huge variety of different assessments are performed. Established assessments are combined with newest technology such as the 3D body scanner. These new methods, the combination of various different assessments from many different disciplines performed annually and the possibility to cover the entire lifespan (together with LIFE Adult) make the LIFE Child study unique. The main potential limitation may lie in the difficulty to maintain a representative cohort especially during follow-up [46]. Due to some of our recruitment strategies, the participants of the LIFE study will likely be characterized by a higher educational and socio-economic status compared to the general population. Whole school classes, especially from inner cities, are approached to minimize this bias. This strategy will help to recruit a sample that adequately represents the population of Leipzig. The idea to invite school classes is a relatively new approach in epidemiologic research. However, researchers of the LIFE Child team already successfully performed a cross-sectional cohort study along with regular public health service examinations in a total of 2,365 healthy schoolchildren [11]. The experiences using this sampling technique in midGermany are promising and may help to improve the response rate [47]. The aim of LIFE Child is to improve the knowledge about normal and abnormal child growth, development, health and disease in contemporary children and adolescents and thus help to develop superior strategies in the prevention and treatment of diseases. Consequently, the results may improve the situation for future generations of children, adolescents and adults in Leipzig and beyond. The study will provide core material for many research projects and the value of the collected data in the LIFE Child study will increase over time. Researchers from everywhere are invited to participate in data analysis and sharing. Moreover, it is possible for researchers to use the templates of the LIFE Child study to generate other disease cohorts for which the LIFE Child HEALTH cohort may contribute controls.

\section{Competing interests}

The authors declare that they have no competing interests.

\section{Authors' contributions}

$\mathrm{MQ}$ and $\mathrm{MH}$ have written the manuscript. AH, AK and WK conceived and designed the study, and led development of study protocols and procedures to obtain ethics approval. $\mathrm{AH}, \mathrm{SN}$ and $\mathrm{CK}$ are responsible for the day-to-day running of the study. MQ, MH, ES, NC, MG, SN and CK have been involved in the development of the study from conception to current practice. $M Q, M H$, ES, NC, MG, SN, CK and AH are actively involved in recruitment. MD established the LIFE Child DEPRESSION cohort, MF carried out the voice examination and $\mathrm{CH}$ implemented the dental examination. WK and MS supervised and reviewed the manuscript. All authors read and approved the final manuscript.

\section{Acknowledgements}

This publication is supported by LIFE - Leipzig Research Centre for Civilization Diseases, Universität Leipzig. LIFE is funded by means of the European Union, by the European Regional Development Fund (ERDF) and by means of the Free State of Saxony within the framework of the excellence initiative. The German Research Foundation (DFG) supports parts of this project (oral examination). Additional funding is being obtained. The authors are extremely grateful to all the families who have taken part in this study, and the whole LIFE Child team.

\section{Funding}

The LIFE child study is funded by means of the European Union, by the European Regional Development Fund (ERDF) and by means of the Free State of Saxony within the framework of the excellence initiative for the period 2009-13. Other official funds from the German Research Foundation (DFG) and the federal ministry of education and research (BMBF) have been obtained for subprojects related to intermediate outcomes. Additional funding is being obtained continuously.

\section{Author details}

${ }^{1}$ LIFE Leipzig Research Centre for Civilization Diseases, University of Leipzig, Philipp-Rosenthalstrasse 27, D-04103 Leipzig, Germany. ²Department of Women and Child Health, Hospital for Children and Adolescents and Centre for Paediatric Research (CPL), University of Leipzig, Liebigstrasse 20a, D-04103 Leipzig, Germany. ${ }^{3}$ IFB Integrated Research and Treatment Centre Adiposity Diseases, University of Leipzig, Philipp-Rosenthalstrasse 27, D-04103 Leipzig, Germany. ${ }^{4}$ Department of Women and Child Health, Hospital for Child and Adolescent Psychiatry, University of Leipzig, Liebigstrasse 20a, D-04103 Leipzig, Germany. 'Section of Phoniatrics and Audiology of the Department of Otorhinolaryngology, University of Leipzig, Liebigstrasse 10-14, D-04103 Leipzig, Germany. ${ }^{6}$ Department of Paediatric Dentistry, University of Leipzig, Nürnbergerstr. 57, D-04103 Leipzig, Germany. ${ }^{7}$ Murdoch Children's Research Institute and Royal Children's Hospital, Flemington Road, Parkville, Melbourne, Victoria 3052, Australia. ${ }^{8}$ University of Melbourne, Melbourne, Melbourne, Victoria 3010, Australia.

Received: 3 October 2012 Accepted: 12 November 2012 Published: 22 November 2012

\section{References}

1. Golding J: Children of the nineties. A longitudinal study of pregnancy and childhood based on the population of Avon (ALSPAC). West Engl Med J 1990, 105(3):80-82.

2. Schulz C, Babisch W, Becker K, Durkop J, Rosskamp E, Seiwert M, Steiner M, Szewzyk R, Ullrich D, Englert N, et al: Environmental Survey for Children-the environmental module of KiGGS. I. Design and research program. Bundesgesundheitsblatt Gesundheitsforschung Gesundheitsschutz 2004, 47(11):1066-1072.

3. Olsen J, Melbye M, Olsen SF, Sorensen TI, Aaby P, Andersen AM, Taxbol D, Hansen KD, Juhl M, Schow TB, et al: The Danish National Birth Cohort-its background, structure and aim. Scand J Public Health 2001, 29(4):300-307.

4. Jaddoe WW, Mackenbach JP, Moll HA, Steegers EA, Tiemeier H, Verhulst FC, Witteman JC, Hofman A: The generation R Study: design and cohort profile. Eur J Epidemiol 2006, 21(6):475-484.

5. Heinrich J, Bruske I, Schnappinger M, Standl M, Flexeder C, Thiering E, Tischer C, Tiesler CM, Kohlbock G, Wenig CM, et al: Two German birth 
cohorts: GINIplus and LISAplus. Bundesgesundheitsblatt Gesundheitsforschung Gesundheitsschutz 2012, 55(6-7):864-874.

6. Brug J, van Stralen MM, Chinapaw MJ, De Bourdeaudhuij I, Lien N, Bere E, Singh AS, Maes L, Moreno L, Jan N, et al: Differences in weight status and energy-balance related behaviours according to ethnic background among adolescents in seven countries in Europe: the ENERGY-project. Pediatr Obes 2012, 7(5):399-411.

7. Lynch J, Smith GD: A life course approach to chronic disease epidemiology. Annu Rev Public Health 2005, 26:1-35.

8. Birmingham K, Doyle A: Ethics and governance of a longitudinal birth cohort. Paediatr Perinat Epidemiol 2009, 23(Suppl 1):39-50.

9. Declaration of Helsinki. http://www.wma.net/en/30publications/10policies/b3/.

10. Edwards P, Cooper R, Roberts I, Frost C: Meta-analysis of randomised trials of monetary incentives and response to mailed questionnaires. J Epidemiol Community Health 2005, 59(11):987-999.

11. Reich A, Muller G, Gelbrich G, Deutscher K, Godicke R, Kiess W: Obesity and blood pressure-results from the examination of 2365 schoolchildren in Germany. Int J Obes Relat Metab Disord 2003, 27(12):1459-1464.

12. Chatfield MD, Brayne CE, Matthews FE: A systematic literature review of attrition between waves in longitudinal studies in the elderly shows a consistent pattern of dropout between differing studies. J Clin Epidemio 2005, 58(1):13-19.

13. Bayley Scales of Infant Development. 3rd edition. http://www. pearsonassessments.com/haiweb/cultures/en-us/productdetail.htm? pid $=015-8027-256 \&$ Community=AI_EC_Screening.

14. Bretschneider T, Koop U, Schreiner V, Wenck H, Jaspers S: Validation of the body scanner as a measuring tool for a rapid quantification of body shape. Skin Res Technol 2009, 15(3):364-369.

15. Simberg S, Sala E, Tuomainen J, Ronnemaa AM: Vocal symptoms and allergy-a pilot study. J Voice 2009, 23(1):136-139.

16. Pabon $\mathrm{P}$, Ternstrom $\mathrm{S}$, Lamarche A: Fourier descriptor analysis and unification of voice range profile contours: method and applications. J Speech Lang Hear Res 2011, 54(3):755-776.

17. Petersen PE, Bourgeois D, Ogawa H, Estupinan-Day S, Ndiaye C: The global burden of oral diseases and risks to oral health. Bull World Health Organ 2005, 83(9):661-669.

18. Gift HC, Reisine ST, Larach DC: The social impact of dental problems and visits. Am J Public Health 1992, 82(12):1663-1668.

19. Goor DA, Sheffy J, Schnall RP, Arditti A, Caspi A, Bragdon EE, Sheps DS: Peripheral arterial tonometry: a diagnostic method for detection of myocardial ischemia induced during mental stress tests: a pilot study. Clin Cardiol 2004, 27(3):137-141

20. Hamburg NM, Keyes MJ, Larson MG, Vasan RS, Schnabel R, Pryde MM, Mitchell GF, Sheffy J, Vita JA, Benjamin EJ: Cross-sectional relations of digital vascular function to cardiovascular risk factors in the framingham heart study. Circulation 2008, 117(19):2467-2474.

21. Rubinshtein R, Kuvin JT, Soffler M, Lennon RJ, Lavi S, Nelson RE, Pumper GM, Lerman LO, Lerman A: Assessment of endothelial function by non-invasive peripheral arterial tonometry predicts late cardiovascular adverse events. Eur Heart J 2010, 31(9):1142-1148.

22. Selamet Tierney ES, Newburger JW, Gauvreau K, Geva J, Coogan E, Colan SD, de Ferranti SD: Endothelial pulse amplitude testing: feasibility and reproducibility in adolescents. J Pediatr 2009, 154(6):901-905.

23. Sabin MA, Clemens SL, Saffery R, McCallum Z, Campbell MW, Kiess W, Crimmins NA, Woo JG, Leong GM, Werther GA, et al: New directions in childhood obesity research: how a comprehensive biorepository will allow better prediction of outcomes. BMC Med Res Methodol 2010, 10:100.

24. Tworoger SS, Hankinson SE: Collection, processing, and storage of biological samples in epidemiologic studies: sex hormones, carotenoids, inflammatory markers, and proteomics as examples. Cancer Epidemiol Biomarkers Prev 2006, 15(9):1578-1581.

25. Schuster S, Hechler C, Gebauer C, Kiess W, Kratzsch J: Leptin in maternal serum and breast milk: association with infants' body weight gain in a longitudinal study over 6 months of lactation. Pediatr Res 2011, 70(6):633-637.

26. Wolf SM, Lawrenz FP, Nelson CA, Kahn JP, Cho MK, Clayton EW, Fletcher JG, Georgieff MK, Hammerschmidt D, Hudson K, et al: Managing incidental findings in human subjects research: analysis and recommendations. J Law Med Ethics 2008, 36(2):219-248. 211.
27. Knoppers BM, Joly Y, Simard J, Durocher F: The emergence of an ethical duty to disclose genetic research results: international perspectives. Eur J Hum Genet 2006, 14(11):1170-1178.

28. Ries NM, LeGrandeur J, Caulfield T: Handling ethical, legal and social issues in birth cohort studies involving genetic research: responses from studies in six countries. BMC Med Ethics 2010, 11(1):4.

29. Andersen LB: Physical activity, fitness and health in children. Scand J Med Sci Sports 2011, 21(2):155-156.

30. Birthcohorts.net. http://www.birthcohorts.net.

31. Korner A, Gelbrich G, Muller G, Reich A, Deutscher K, Godicke R, Gronemann B, Kiess W: Critical evaluation of methods for determination of body fat content in children: back to basic parameters? Horm Metab Res 2007, 39(1):31-40.

32. Kiess W, Sergejev E, Korner A, Hebebrand J: Is it possible to treat obesity in children and adolescents? Bundesgesundheitsblatt Gesundheitsforschung Gesundheitsschutz 2011, 54(5):527-532.

33. Muller MJ, Asbeck I, Mast M, Langnase K, Grund A: Prevention of obesity--more than an intention. Concept and first results of the Kiel obesity prevention study (KOPS). Int J Obes Relat Metab Disord 2001, 25(Suppl 1):S66-74.

34. Kromeyer-Hauschild K, Zellner K: Trends in overweight and obesity and changes in the distribution of body mass index in schoolchildren of Jena, East Germany. Eur J Clin Nutr 2007, 61(3):404-411.

35. Bluher S, Meigen C, Gausche R, Keller E, Pfaffle R, Sabin M, Werther G, Odeh R, Kiess W: Age-specific stabilization in obesity prevalence in German children: a cross-sectional study from 1999 to 2008. Int J Pediatr Obes 2011, 6(2-2):e199-206.

36. Flegal KM, Tabak CJ, Ogden CL: Overweight in children: definitions and interpretation. Health Educ Res 2006, 21(6):755-760.

37. Holling H, Erhart M, Ravens-Sieberer U, Schlack R: Behavioural problems in children and adolescents. First results from the German health interview and examination survey for children and adolescents (KiGGS). Bundesgesundheitsblatt Gesundheitsforschung Gesundheitsschutz 2007, 50(5-6):784-793.

38. Erhart M, Holling H, Bettge S, Ravens-Sieberer U, Schlack R: The German health interview and examination survey for children and adolescents (KiGGS): risks and resources for the mental development of children and adolescents. Bundesgesundheitsblatt Gesundheitsforschung Gesundheitsschutz 2007, 50(5-6):800-809.

39. Birmaher B, Ryan ND, Williamson DE, Brent DA, Kaufman J, Dahl RE, Perel J, Nelson B: Childhood and adolescent depression: a review of the past 10 years. Part I. J Am Acad Child Adolesc Psychiatry 1996, 35(11):1427-1439.

40. Pearce N, Ait-Khaled N, Beasley R, Mallol J, Keil U, Mitchell E, Robertson C: Worldwide trends in the prevalence of asthma symptoms: phase III of the international study of asthma and allergies in childhood (ISAAC). Thorax 2007, 62(9):758-766.

41. von Mutius $\mathrm{E}$ : The rising trends in asthma and allergic disease. Clin Exp Allergy 1998, 28(Suppl 5):45-49. discussion 50-41.

42. Centres for Disease control and Prevention. http://www.cdc.gov/oralhealth/ publications/library/burdenbook/index.htm.

43. Nicolai T, Bellach B, Mutius EV, Thefeld W, Hoffmeister H: Increased prevalence of sensitization against aeroallergens in adults in West compared with East Germany. Clin Exp Allergy 1997, 27(8):886-892.

44. Golding J: The Avon longitudinal study of parents and children (ALSPAC)-study design and collaborative opportunities. Eur J Endocrinol 2004, 151(Suppl 3):U119-123.

45. Vandentorren S, Bois C, Pirus C, Sarter H, Salines G, Leridon H: Rationales, design and recruitment for the Elfe longitudinal study. BMC Pediatr 2009, 9:58.

46. Alonso A, Segui-Gomez M, de Irala J, Sanchez-Villegas A, Beunza JJ, Martinez-Gonzalez MA: Predictors of follow-up and assessment of selection bias from dropouts using inverse probability weighting in a cohort of university graduates. Eur J Epidemiol 2006, 21(5):351-358.

47. Hirsch C, Turp JC: Temporomandibular pain and depression in adolescents-a case-control study. Clin Oral Investig 2010, 14(2):145-151.

doi:10.1186/1471-2458-12-1021

Cite this article as: Quante et al:: The LIFE child study: a life course approach to disease and health. BMC Public Health 2012 12:1021. 